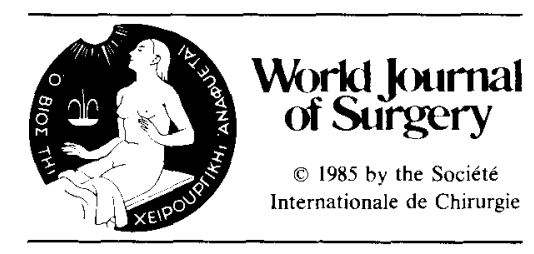

\title{
Splenectomy for Splenomegaly and Secondary Hypersplenism
}

\author{
William W. Coon, M.D. \\ Department of Surgery, The University of Michigan Hospitals, Ann Arbor, Michigan, U.S.A.
}

\begin{abstract}
Splenomegaly and secondary hypersplenism may be associated with acute and chronic infections, autoimmune states, portal hypertension or splenic vein thrombosis, and a number of infiltrative and neoplastic conditions involving the spleen. Our experience and that of others with these various conditions demonstrates that the decision to perform splenectomy should be based on well-defined and often strictly limited indications. Except for idiopathic splenomegaly, the presence and severity of secondary hypersplenism or severely symptomatic splenomegaly should be well documented. In each case, the potential for palliation and known mean duration of expected response must be weighed against the increased morbidity and mortality of splenectomy (as compared to operation for "primary" hypersplenism).
\end{abstract}

Hypersplenism is a nonspecific term indicating that the spleen may be functioning in a manner having a deleterious effect on the blood cells of the host. The usual criteria utilized to indicate the presence of this condition are: (a) splenomegaly; (b) a clinically significant decrease in one or more of the cellular elements of the blood; (c) the presence of a normal or hypercellular bone marrow; and (d) correction or improvement of the cytopenia by splenectomy. However, in clinical application, all of these elements may not be satisfied. Splenomegaly is not and should not be present in idiopathic thrombocytopenic purpura. A cytopenia present in several of the myeloproliferative disorders may respond to splenectomy in spite of the presence of decreased cellular precursors in the bone marrow.

Reprint requests: William W. Coon, M.D., Section of General Surgery, D2214, Medical Professional Building, University of Michigan Hospitals, Ann Arbor, Michigan 48109, U.S.A.
The separation of hypersplenism into primary and secondary categories is also imprecise. The diseases usually included under "primary" hypersplenism are those in which the fundamental defect is thought to be related to a congenital or acquired alteration in cell membrane or structure of hematopoietic cells (idiopathic thrombocytopenic purpura, acquired hemolytic anemia, some of the congenital hemolytic anemias, etc.).

This discussion will be confined to selected entities usually considered to be associated with "secondary" hypersplenism in which splenomegaly and altered splenic microcirculation may bring about splenic sequestration of erythrocytes, neutrophils, or platelets. Here, again, the specificity of this terminology is debatable since, in several secondary hypersplenic conditions (Felty's syndrome, hairy cell leukemia), altered cell structure may also play a role in the pathophysiologic mechanism of cytopenia.

Secondary hypersplenism has been associated with certain acute and chronic infections, autoimmune states (Felty's syndrome, systemic lupus erythematosus), infiltrative and neoplastic conditions involving the spleen (sarcoidosis, Gaucher's disease, several myeloproliferative disorders, and lymphomas) and occasionally with "congestive splenomegaly" brought about by portal hypertension or splenic vein thrombosis.

\section{Leukemia}

Splenectomy has been performed for several types of leukemia for more than 100 years, but its value and limitations have only been defined in the past few years.

Only in the relatively rare hairy cell leukemia is splenectomy the initial treatment of choice. Although this condition was recognized as a distinct 
entity more than 25 years ago, in the past 10 years other related conditions have been appropriately excluded as a result of a better definition of marrow and splenic pathological findings and utilization of the tartrate-resistant acid phosphatase stain which is positive in $\mathbf{8 5 - 9 0 \%}$ of cases. This usually slowly progressive disease is probably a variant form of chronic lymphocytic leukemia since the cell of origin appears to be a transformed lymphocyte. Median survival after diagnosis is $3-4$ years, but many patients live for 8-10 years or longer. Responses to intensive chemotherapy or to corticosteroids have been poor. Splenectomy is indicated if the patient develops a hypersplenic complication such as severe anemia, thrombocytopenia, or granulocytopenia. In our experience with 17 patients followed at our institution during the past 10 years [1], 16 have had a splenectomy for one of these indications. There have been no operative deaths and only 1 postoperative superficial wound infection. Nine of the 16 splenectomized patients are still alive with a median postoperative survival of more than 42 months. Only 2 patients have required postoperative chemotherapy with lowdose chlorambucil. Thirteen of 16 have achieved a satisfactory hematologic response (hematocrit: 35 vol \% or above; granulocytes: $1,000 / \mathrm{mm}^{3}$ or more; platelets: $100,000 / \mathrm{mm}^{3}$ or greater) after operation. In a recent analysis of 391 cases [2], patients who had a splenectomy survived longer than patients who did not undergo surgery; operative mortality rate was $2 \%$. About $80 \%$ of patients still achieve an "acceptable hematologic response" (as previously defined) [2]. In patients who fail to achieve an adequate response to splenectomy, low-dose chlorambucil (4 mg/day) has been of value [3]. Recently, bone marrow transplantation [4] or daily administration of alpha interferon [5] have been proposed as additional therapeutic modalities.

While many patients with chronic lymphocytic leukemia live for 5-10 years with little or no treatment, a small fraction may develop hypersplenic complications or massive symptomatic splenomegaly, usually relatively late in the course of this disease. Of our 15 patients operated on for one of these indications [1], 2 died after operation from persistent thrombocytopenic bleeding. Four patients with hemolytic anemia, 1 with pancytopenia, and 4 with symptomatic splenomegaly had excellent responses to operation with a mean survival of greater than 4 years. Of 6 patients with thrombocytopenia, only 2 achieved a satisfactory rise in platelet count. Others have reported similar results $[6,7]$.

The utilization of splenectomy in the management of chronic granulocytic leukemia (CGL) has been much more controversial. In our hospital, the operation has been performed primarily for acute symptoms and fear of splenic rupture, severe thrombocytopenia, or highly symptomatic splenomegaly [1]. Of 11 patients, 8 were operated on in the "accelerated phase" of their disease [8] in which median survival is only 3-6 months. Three died postoperatively. In 2 patients splenectomy was performed as a preliminary to bone marrow transplantation and both are alive (at 1 and 3 years, respectively). Many reports attributing value to splenectomy for this condition have been anecdotal. However, several recent nonrandomized comparisons of operation versus no operation early in the chronic phase of CGL have shown that splenectomy does not delay progression from the chronic to the blastic phase and does not prolong survival $[9,10]$. In a recent prospective trial, similar conclusions were reached [11].

\section{Stage IV Lymphoma}

On rare occasions, patients with far-advanced Hodgkin's disease or non-Hodgkin's lymphoma will develop severe hypersplenism which is refractory to chemotherapy, or a cytopenia interferes with administration of adequate doses of chemotherapeutic agents. In our experience with 5 such patients, 1 died 3 weeks postoperatively with pneumonia. The other 4 achieved a very satisfactory cytologic response with survival from 5 months to more than 8 years. The entire spectrum of cytopenias were encountered: thrombocytopenia in 1 patient, hemolytic anemia in 1, hemolytic anemia and thrombocytopenia in another, and pancytopenia in the fourth. In 3 patients a sustained remission of hypersplenism was achieved until death from lymphoma. The fourth and longest surviving patient had a relapse of a Coombs'-positive hemolytic anemia 2 years after operation which responded to steroid therapy and then remained in remission until a terminal relapse $81 / 2$ years after splenectomy.

\section{Sarcoidosis}

Although 6\% of patients with sarcoidosis are said to have splenomegaly [12], the need for splenectomy is extremely uncommon. In the largest reported series, splenectomy was performed for symptomatic splenomegaly in 7 patients, for infarction or rupture in 2, for hypersplenism in 5 (all of whom responded), and for other indications in 2 [13]. In our personal experience with 8 patients, diagnosis was the indication in 4 individuals who had no prior diagnosis and manifestations compatible with possible lymphoma (fever of undetermined origin, 
splenomegaly, para-aortic lymphadenopathy, etc.). One patient had symptomatic splenomegaly. In the other 3 patients, surgery was performed for hemolytic anemia or neutropenia and all achieved remission after splenectomy.

\section{Agnogenic Myeloid Metaplasia (AMM)}

Selected patients with this myeloproliferative disorder may obtain palliative benefit from splenectomy, but operative morbidity and mortality rates are appreciable and it is doubtful whether removal of the spleen affects prognosis [14]. Diagnosis is based on the presence of splenomegaly and immature myeloid and erythroid cells in peripheral blood, anisocytosis and poikilocytosis, and variable degrees of fibrosis in bone marrow. For determination of prognosis and decisions regarding operative benefit, patients with "primary" AMM should be distinguished from those in whom AMM evolves following treatment for polycythemia rubra vera or essential thrombocythemia.

Our operative experience with this condition includes 34 patients between the ages of 40 and 76 years, 27 of whom had primary AMM. Splenectomy was performed for hypersplenism in $\mathbf{2 0}$ individuals, for symptomatic splenomegaly in 11 , in association with other operations in 2 , and for traumatic rupture in 1 patient. The postoperative hematologic response could not be evaluated in 6 patients with hypersplenism because of postoperative death, persistent chronic gastrointestinal bleeding, or myelosuppressive chemotherapy. In 10 patients with chronic anemia and decreased erythrocyte survival, 8 had a postoperative increase in the hematocrit reading of $5 \mathrm{vol} \%$ or more which was maintained for periods of 6 months to more than 8 years. A sustained increase in platelet count (for more than 1 year) was observed in 3 of 4 thrombocytopenic patients.

Symptomatic splenomegaly is manifested by chronic left upper quadrant abdominal and back pain and early satiety (from gastric displacement). Splenic weight in this group ranged from 980 to $4,200 \mathrm{~g}$. All survivors obtained significant symptomatic benefit.

Four postoperative deaths resulted from leukemic conversion, gastrointestinal bleeding, acute hepatic necrosis, or sepsis, and morbidity from bleeding or sepsis was encountered in 12 patients. Mean duration of survival following splenectomy was 22 months for men and 46 months for women with primary AMM but only 8 months for secondary AMM. The majority of late deaths were due to leukemic conversion or to gastrointestinal bleeding.

Since morbidity and mortality are considerable and survival is limited after splenectomy, careful selection of patients and intensive preoperative preparation are essential. Our experience with a very short postoperative survival in subjects with secondary AMM indicates that surgery in this subgroup is of questionable benefit. In patients with chronic anemia requiring frequent transfusion, a source of continued gastrointestinal blood loss should be eliminated. Determination of ${ }^{51} \mathrm{Cr}$ erythrocyte survival may help separate those patients with hypersplenic pooling and sequestration from those with marrow production failure. Five to ten percent of patients with myeloid metaplasia will have secondary portal hypertension [15], but an adjunctive splenorenal shunt is seldom indicated; Schwartz [16] has reported that in 6 patients with AMM and increased portal pressures, splenectomy resulted in a decrease in portal pressures to normal or near normal in all. Preoperative assessment of coagulation profile and platelet function is important because much of the immediate morbidity is related to thrombotic and hemorrhagic complications. Qualitative platelet abnormalities are frequently demonstrable in patients with myeloproliferative disorders, and, if present, platelet transfusion during operation may be helpful. In addition, Silverstein and Remine [15] have found laboratory evidence of subclinical disseminated intravascular coagulation (decreased platelets and factors $\mathrm{V}$ and VIII and increased fibrin degradation products) in $12 \%$ of these patients and advise against surgery in this circumstance.

We now restrict splenectomy in this condition to patients with primary myeloid metaplasia and hypersplenic anemia or thrombocytopenia or symptomatic splenomegaly whose preoperative assessment indicates an acceptable operative risk.

\section{Felty's Syndrome}

This entity is characterized by splenic neutropenia (total white blood cell count less than $3,500 / \mathrm{mm}^{3}$ and neutrophil count less than $2,000 / \mathrm{mm}^{3}$ ) developing in a patient with rheumatoid arthritis and usually accompanied by splenomegaly and anemia and occasionally by cutaneous ulcers of the leg. There has been considerable debate in recent years concerning the value of splenectomy in preventing episodes of infection. Since only approximately 1 in 300 patients with rheumatoid arthritis develop this syndrome [17], no prospective trials have been conducted. Many physicians have tried to manage problems of sepsis with antibiotic therapy alone or in combination with administration of lithium in an attempt to stimulate granulopoietic precursors in the bone marrow. In our recent nonrandomized assessment of 20 evaluable patients receiving nonoperative management and 20 splenectomized 
patients [18], we have attempted to refine possible criteria for operation.

Among the 20 subjects not undergoing surgery, 16 presented with an infection and/or a leg ulcer. There have been 2 deaths from sepsis and 1 episode of severe pneumonia. Leg ulcers persisted in 5 of 6 patients, healing in 1 after a 7-year period of observation. Of 5 patients given a trial of lithium in doses of 900 to $1,800 \mathrm{mg} / \mathrm{day}$, only 1 achieved a satisfactory granulocytic response.

Of the 20 splenectomized patients, 4 were lost to follow-up after hospital discharge, 2 having achieved a satisfactory neutrophil response to greater than $2,000 / \mathrm{mm}^{3}$. There was no operative mortality. In the remaining 16 patients who have been observed for 6 months to 20 years (mean: 4 years), 13 have had a prompt and sustained leukocyte (above 3,500) and neutrophil response (above 2,000). None have had further infections. Of the 3 patients with follow-up who were splenectomy "failures" (unsatisfactory cytologic response), 1 died of sepsis 5 years later and a second has had an episode of pharyngitis responsive to antibiotics. Of 5 patients with leg ulcers, 3 have healed; 1 patient was lost to follow-up. No clinical or laboratory criteria have been found that can predict response to splenectomy. In patients who had a satisfactory neutrophil response to splenectomy or who had a remission during nonoperative management, anemia also improved. The infections that appeared after splenectomy occurred in patients with an inadequate neutrophil response. Other authors have also reported correction of neutropenia and relief from recurrent infection in $60-80 \%$ of patients undergoing splenectomy $[17,19,20]$.

Our data on the natural history of Felty's syndrome in patients not undergoing surgery lead us to believe that, with rare exceptions, hematologic abnormalities alone are not a sufficient indication for operation unless the patient has an associated severe hemolytic anemia or thrombocytopenia. Although neutropenia of fewer than 500 cells $/ \mathrm{mm}^{3}$ has been proposed as an indication for operation, we found no correlation between lowest neutrophil count and the development, severity, or frequency of infection. On the other hand, after the appearance of serious or recurrent infection, splenectomy appears to be of value regardless of the severity of the neutropenia. Although our sample is small, the likelihood of healing of a leg ulcer seems improved after splenectomy.

\section{"Congestive Splenomegaly"}

This nonspecific term includes a spectrum of conditions of varying etiology and severity. At one end of the spectrum is Banti's syndrome in a patient with frank cirrhosis, portal hypertension, and splenomegaly with or without clinically significant hypersplenism. At the other end is the individual with idiopathic splenomegaly and/or hypersplenism in whom, after splenectomy, the pathologist describes "congestion" of the spleen but no obvious liver disease or extrahepatic portal or splenic venous obstruction is demonstrable. Between these extremes are many patients with parasitic, "infiltrative" (sarcoidosis, amyloidosis), and myeloproliferative disorders in whom variable degrees of intrahepatic or extrahepatic portal venous obstruction may play a pathogenic role in the development of splenomegaly and hypersplenism.

Splenectomy is the treatment of choice in patients with splenic vein thrombosis, "left-sided portal hypertension," and bleeding esophageal varices. The indication for operation is almost always related to the presence of esophageal varices rather than clinically significant hypersplenism. Although chronic pancreatitis is the most frequent underlying cause of isolated splenic vein thrombosis, one should be aware that previously undiagnosed pancreatic carcinoma or lymphoma can also produce this condition.

Most surgeons would now agree that splenectomy alone is inappropriate in patients with hepatic cirrhosis, portal hypertension, bleeding esophageal varices, and signs of hypersplenism. Warren and associates [21] have recently reported that platelet counts less than $50,000 / \mathrm{mm}^{3}$ were found in $8-10 \%$ of their patients presenting with variceal bleeding; thrombocytopenia was observed more frequently in patients with nonalcoholic as compared to those with alcoholic liver disease. Boivin [22] observed a lower frequency of thrombocytopenia in patients with cirrhosis ( 7 of 185 cases with platelets less than $50,000 / \mathrm{mm}^{3}$ ). In his experience the level of thrombocytopenia present in these individuals did not affect mortality or morbidity after operations for portal decompression. While most of the currently utilized shunt procedures for management of portal hypertension leave the spleen intact, the majority of patients with associated thrombocytopenia will respond with an increase in platelet count postoperatively, but in some, the rise may not be sustained [23] and the increase in platelets (or leukocytes) will not reach normal values [24]. Splenectomy should be reserved for the very rare patient with severe residual thrombocytopenia after shunt.

In our experience with idiopathic splenomegaly and hypersplenism [25], we have encountered 3 patients in whom the diagnosis of relatively mild cirrhosis was made only at the time of splenectomy and liver biopsy. Thrombocytopenia (platelet counts: 38 to 68,000 ) improved after splenectomy, 
and platelet counts have remained normal for periods of follow-up of 1 to 8 years. In 4 other patients with idiopathic neutropenia (2 with associated thrombocytopenia), the only histologic finding was "splenic congestion" without evidence of liver disease. All achieved a satisfactory cytologic response to splenectomy.

Portal hypertension secondary to either extrahepatic or intrahepatic portal obstruction in patients with hypersplenism associated with myeloproliferative disorders [26] may add to morbidity and mortality. As mentioned in prior discussion, many of these patients achieve little or only very short-term benefit from an operation and, as Schwartz [16] has shown, adjunctive shunt procedures are seldom indicated. However, awareness of the possible presence of portal hypertension, and also platelet and coagulative abnormalities [15] in patients with these conditions is important because some of these individuals will require urgent operations for other problems. As Wasserman and Gilbert [27] have reported for patients with polycythemia vera (and it is equally true in other myeloproliferative conditions), any abdominal operation is associated with an appreciable mortality and morbidity from hemorrhage or thrombosis.

\section{Gaucher's Disease and Other Reticuloendothelioses}

The benefit of splenectomy in these conditions is chiefly in selected patients with Gaucher's disease. This hereditofamilial deficiency of acid-beta-glucosidase results in progressive accumulation of glucosylceramide in the spleen, bringing about massive splenomegaly and frequently secondary hypersplenism. Since this is a disease of the Jewish population, primarily Ashkenazi Jews, the greatest experience has been accumulated in Israel and in Jewish hospitals in other countries. Matoth and Fried [28] have reported 16 splenectomies without mortality in patients of ages 5 to 47 years; splenectomy was performed principally for thrombocytopenia with a prompt increase in platelets which is usually maintained for years. The effect on anemia is less dramatic. Similar results have been obtained in several other small series of patients $[29,30]$. Our limited experience with 3 patients is similar. All had a prompt and sustained remission of thrombocytopenia. An associated anemia in a 4-year-old female also improved. Although there has been some concern that splenectomy may worsen the clinical course and accelerate the progression of orthopedic problems, others feel that this impression is erroneous because the more severely affected young patients are the ones who have early splenectomy and are more likely to develop later orthopedic problems [31].
In the past, splenectomy has been performed in a few patients with Niemann-Pick disease, but follow-up of these subjects with a very limited prognosis has demonstrated no alteration in survival, although anemia improved moderately in several [32].

\section{Tropical Splenomegaly Syndrome}

This condition, recognized in Africa and New Guinea for many years, is seen in patients with high titers of antimalarial antibodies and is associated with lymphocytosis in the bone marrow, anemia and occasionally mild leukopenia and thrombocytopenia, reactive macroglobulinemia, increased IgM levels, and reduced serum complement $\left(\mathrm{C}_{3}\right)$ [33]. A causal relationship to malaria has not been established. Splenectomy has been shown to improve the cytopenias [34, 35]. Many patients will respond to prolonged antimalarial therapy [36]; splenectomy is now reserved for those patients in whom anemia fails to respond to antimalarial drugs and those with symptomatic splenomegaly (chronic abdominal pain) [34].

\section{Idiopathic Splenomegaly and Hypersplenism}

A mélange of "idiopathic" conditions have been described over the past 40 years. Wiseman and Doan [37] classified a group of patients with splenomegaly and neutropenia without specific splenic histology as "primary splenic neutropenia." More recently, Dacie and associates [38, 39] have followed these patients with "non-tropical idiopathic splenomegaly" and hypersplenism in whom no diagnosis was made after splenectomy; 4 have subsequently developed lymphoma.

Our patients with idiopathic splenomegaly [25] have differed from those of Dacie and of other investigators $[40,41]$ but are similar to those of Goonewardene and co-workers [42]. Although 18 of 28 patients with splenomegaly of undetermined origin had some degree of hypersplenism (hematocrit $<30 \mathrm{vol} \%$, leukocytes $<3,500 / \mathrm{mm}^{3}$ or neutrophils $<2,000 / \mathrm{mm}^{3}$ or platelets $<100,000 / \mathrm{mm}^{3}$ ), the cytopenias were usually mild; splenectomy was performed for detection of possible lymphoma. No lymphoma was found at the time of operation and only 1 patient has subsequently had this diagnosis made. Only 7 had a specific diagnosis made as a result of the operation (cirrhosis, splenic cyst, sarcoidosis).

This experience with a group of patients who were relatively young (mean age: 28 years) has led us to be more conservative with respect to recom- 
mending splenectomy, provided that no other manifestations compatible with the diagnosis of lymphoma are present. Many who are young, asymptomatic, and with a history of recent infection can be closely watched and a decision regarding splenectomy deferred.

\section{Réumé}

La splénomégalie avec hypersplénisme secondaire relève de multiples causes: infection aigue ou chronique, états autoimmunologiques, hypertension portale, thrombose de la veine splénique, lésions tumorales spléniques. L'expérience de l'auteur qui rejoint celle de nombreux collégues lui permet d'affirmer que les indications de la splénectomie doivent être bien définies et sont strictement limitées. A l'exception de la splénomégalie idiopathique, l'existence et l'intensité de l'hypersplénisme, l'importance des symptomes provoqués par la splénomégalie doivent être aprréciées avec précision. Dans chaque cas le potentiel de la rémission de l'affection et la durée de la rémission doivent être pris en considération en fonction de l'éventuelle morbidité et de l'éventuelle mortalité de la splénectomie (par comparaison avec la splénectomie pour hypersplénisme primaire).

\section{Resumen}

Eplenomegalia e hiperesplenismo secundario pueden estar asociados con infecciones agudas y crónicas, estados autoinmunes (síndrome de Felty, lupus eritematoso sistémico), "esplenomegalia congestiva" por hipertensión portal o trombosis de la vena esplénica y con una variedad de entidades de tipo infiltrativo y neoplásico que afectan al bazo (sarcoidosis, enfermedad de Gaucher, varios desórdenes mieloproliferativos y linfomas). Nuestra experiencia, y aquella de otros autores, con tales condiciones demuestra que la decisión de realizar esplenectomía debe estar fundamentada en indicaciones bien definidas y estrictamente limitadas. Excepto en casos de esplenomegalia idiopática, la presencia y severidad del hiperesplenismo secundario o de esplenomegalia severamente sintomática debe ser bien documentada. En cada caso debe determinarse el potencial de paliación y la duración de la respuesta que se espera obtener frente a la incrementada morbilidad y mortalidad de la esplenectomía (en comparación con la operación que se realiza por hiperesplenismo "primario").

\section{References}

1. Coon, W.W.: The limited role of splenectomy in patients with leukemia. Surg. Gynecol. Obstet. (in press)
2. Jansen, J., Hermans, J.: Splenectomy in hairy cell leukemia. A retrospective multicenter analysis. Cancer 46:2066,1981

3. Golomb, H.M.: Progress report on chlorambucil therapy in postsplenectomy patients with progressive hairy cell leukemia. Blood 57:464, 1981

4. Cheever, M.A., Fefer, A., Greenberg, P.E., Appelbaum F., Armitage, J.O., Buckner C.D., Sale, G.E., Storb, R., Witherspoon, R.P., Thomas, E.D.: Treatment of hairy-cell leukemia with chemoradiotherapy and identical-twin bone marrow transplantation. N. Engl. J. Med. 30:479, 1982

5. Quesada, J.R., Reuben, J., Manning, J.T., Hersh, E.M., Gutterman, J.U.: Alpha interferon for induction of remission in hairy cell leukemia. N. Engl. J. Med. 310:15,1984

6. Christensen, B.E., Hansen, L.K., Kristensen, J.K., Videboek, A.: Splenectomy in haematology: Indications, results and complications in 41 cases. Scand. J. Haematol. 7:247, 1970

7. Holt, J.M., Witts, L.J.: Splenectomy in leukaemia and the reticuloses. Q. J. Med. 35:369, 1966

8. Karanas, A., Silver, R.T.: Characteristics of the terminal phase of chronic granulocytic leukemia. Blood 32:445, 1968

9. Ihde, D.C., Canellos, G.P., Schwartz, J.H., DeVita, V.T.: Splenectomy in the chronic phase of chronic granulocytic leukemia. Ann. Intern. Med. 84:17, 1976

10. Baccarani, M., Corbelli, G., Tuca, S., and the Italian Cooperative Study Group on Chronic Myeloid Leukemia: Early splenectomy and polychemotherapy versus polychemotherapy alone in chronic myeloid leukemia. Leuk. Res. 5:149, 1981

11. Medical Research Council's Working Party for Therapeutic Trials in Leukemia: Randomized trial of splenectomy in $\mathrm{Ph}^{\mathrm{l}}$-positive chronic granulocytic leukaemia, including an analysis of prognostic features. Br. J. Haematol. 54:415, 1983

12. James, D.G., Neville, E., Siltzbach, L.E.: A worldwide review of sarcoidosis. Ann. N.Y. Acad. Sci. 278:321, 1976

13. Webb, A.K., Mitchell, D.N., Bradstreet, C.M.P., Salsbury, A.J.: Splenomegaly and splenectomy in sarcoidosis. J, Clin. Pathol. 32:1050, 1979

14. Coon, W.W., Liepman, M.K.: Splenectomy for agnogenic myeloid metaplasia. Surg. Gynecol. Obstet. 154:561, 1982

15. Silverstein, M.N., Remine, W.H.: Splenectomy in myeloid metaplasia. Blood 53:515, 1979

16. Schwartz, S.I.: Myeloproliferative disorders. Ann. Surg. 182:464, 1975

17. Green, R.A., Fromke, V.L.: Splenectomy in Felty's syndrome. Ann. Intern. Med. 64:1265, 1966

18. Coon, W.W.: Felty's syndrome: When is splenectomy indicated? Am. J. Surg. 149:272, 1985

19. Moore, R.A., Brunner, C.M., Sanduskey, W.R., Byrd, S.L.: Felty's syndrome. Long-term follow-up after splenectomy. Ann. Intern. Med. 75:381, 1971

20. Laszlo, J., Jones, R., Silverman, H.R., Banks, P.R.: Splenectomy for Felty's syndrome. Arch. Intern. Med. 138:597, 1978

21. Warren, W.D., Millikan, W.J., Jr., Henderson, J.M., Rasheed, M.E., Solam, A.A.: Selective variceal decompression after splenectomy or splenic vein thrombosis. Ann. Surg. 199:694, 1984 
22. Boivin, P.: Les thrombopénies des cirrhoses, sontelles une indication de splénectomie? Acta Gastroenterol. Belg. 44:203, 1981

23. Morris, P.W., Patton, T.B., Bolint, J.A., Hirshowitz, B.I.: Portal hypertension, congestive splenomegaly and portacaval shunt. Gastroenterology 42:555, 1962

24. Hutson, D.G., Zeppa, R., Levi, J.U., Schiff, E.R., Livingstone, A.S., Fink, P.L.: The effect of the distal splenorenal shunt on hypersplenism. Ann. Surg. I85:605, 1977

25. Knudson, P., Coon, W., Schnitzer, R., Liepman, M.: Splenomegaly without an apparent cause. Surg. Gynecol. Obstet. 155:705, 1982

26. Shaldon, S., Sherlock, S.: Portal hypertension in the myeloproliferative syndrome and the reticuloses. Am. J. Med. 32:758, 1962

27. Wasserman, L.R., Gilbert, H.S.: Surgery in polycythemia vera. N. Engl. J. Med. 269:1226, 1963

28. Matoth, Y., Fried, K.: Chronic Gaucher's disease: Clinical observations on 34 patients. Isr. J. Med. Sci. $1: 521,1965$

29. Medoff, A.S., Bayrd, E.D.: Gaucher's disease in 29 cases: Hematologic complications and effect of splenectomy. Ann. Intern. Med. 40:481, 1954

30. Aufses, A.H., Jr., Salky, B.M.: The surgical management of Gaucher's disease. In Gaucher's Disease: A Century of Delineation and Research, R.J. Desnick, S. Gott, G.A. Grabowski, editors. New York, Alan R. Liss, Inc., 1982, pp. 107-129

31. Beighton, P., Goldblatt, J, , Sachs, S.: Bone involvement in Gaucher's disease. In Gaucher's Disease: A Century of Delineation and Research, R.J. Desnick, S. Gott, G.A. Grabowski, editors. New York, Alan R. Liss, Inc., 1982, pp. 603-616
32. Crocker, A.C., Barber, S.: Niemann-Pick disease: A review of eighteen cases. Medicine 437:1, 1958

33. Ziegler, J.L., Stuiver, P.C.: Tropical splenomegaly in a Rwandon kindred in Uganda. Br. Med. J, 3:79, 1972

34. Hamilton, P.J.S., Richmond, J., Donaldson, G.W.K., Williams, R., Hutt, M.S.R., Lugumba, V.: Splenectomy in "Big Spleen Disease." Br. Med. J. 3:823, 1967

35. Pryor, D.S.: Splenectomy in tropical splenomegaly. Br. Med. J. 3:825, 1967

36. Watson-Williams, E.J., Allan, N.C.: Idiopathic tropical splenomegaly syndrome in Ibadan. Br. Med. J. 4:793, 1968

37. Wiseman, B.K., Doan, C.A.: Primary splenic neutropenia. Ann. Intern. Med. 16:1097, 1942

38. Dacie, J.V., Brain, M.C., Harrison, C.V., Lewis, S.M., Worlledge, S.M.: Nontropical idiopathic splenomegaly ("primary hypersplenism"); a review of ten cases and their relationship to malignant lymphoma. Br. J. Haematol. 17:317, 1969

39. Dacie, J.V., Galton, D.A.G., Cordon-Smith, E.C., Harrision, C.V.: Nontropical "idiopathic splenomegaly"; a follow-up study of ten patients described in 1969. Br. J. Haematol. 38:185, 1978

40. Hermann, R.E., DeHaven, K.E., Hawk, W.A.: Splenectomy for the diagnosis of splenomegaly. Ann. Surg. 168:896, 1968

41. Long, J.C., Aisenberg, A.A.: Malignant lymphoma diagnosed at splenectomy and idiopathic splenomegaly. Cancer 33:1054, 1974

42. Goonewardene, A., Bourke, J.B., Ferguson, R., Toghill, P.J.: Splenectomy for undiagnosed splenomegaly. Br. J. Surg. 66:62, 1979 